\title{
A fronteira em movimento: relações luso-castelhanas na segunda metade do século XVIII
}

\author{
FÁBIO KÜHN*
}

Resumo: Pretende-se discutir a noção de fronteira no Rio Grande do Sul colonial, onde sugerimos uma visão alternativa do povoamento sulino, baseados nos registros paroquiais do século XVIII. Parece ser mais apropriado considerar o espaço fronteiriço colonial enquanto uma "fronteira em movimento", com intensa circulação humana e econômica, dentro de um contexto demográfico diversificado.

Abstract: We intend to discuss the concept of frontier in the colonial Rio Grande do Sul, suggesting an alternative understanding of the southern settlement, supported on the eighteenth century parish records. It seems to be more appropriate if we consider the colonial frontier space as a "moving frontier", with an intense human and economic circulation, within a diversified demographical context.

Palavras-chave: Fronteira. Migrações. Rio Grande do Sul colonial.

Key words: Frontier. Migrations. Colonial Rio Grande do Sul.

\section{Introdução}

A historiografia regional sobre o período da Dominação Espanhola (1763-1776) ${ }^{1}$ construiu uma representação idealizada do contexto demográfico existente durante os anos de ocupação castelhana no atual Rio Grande do Sul, procurando configurar uma

Professor assistente do Departamento de História da UFRGS, Porto Alegre, Brasil. Email: brasil@ifch.ufrgs.br

Denomina-se este período (1763-1776) como de "Dominação Espanhola", em função da ocupação militar hispânica de boa parte do Rio Grande de São Pedro (atual Rio Grande do Sul). No século XVIII, o Rio Grande foi o território alvo das maiores disputas bélicas e diplomáticas entre as Coroas lusa e espanhola na América do Sul. 
situação de fronteira excludente no Rio Grande de São Pedro. Esta representação da história rio-grandense procurou constituir uma exclusão total das populações indígenas e espanholas no Continente do Rio Grande, também presente nas representações construídas pela historiografia de matriz lusitana acerca das Missões jesuíticas ou sobre as relações luso-brasileiras com o Prata. Assim, procurou excluir qualquer possibilidade de influência hispânica ou mesmo autóctone na formação histórica rio-grandense, construindo um Rio Grande exclusivamente lusitano. ${ }^{2}$

Sem desconsiderar a importância do povoamento e ocupação luso-brasileira da região sulina, aponta-se para os variados influxos demográficos de um território fronteiriço. Através do levantamento dos registros paroquiais do período 1747-1780 das principais freguesias sul-rio-grandenses, sugere-se um novo quadro de referência, onde o espaço fronteiriço colonial procura ser compreendido enquanto uma "fronteira em movimento", com intensa circulação de homens e mercadorias, dentro de um contexto demográfico extremamente heterogêneo. Pretende-se demonstrar, assim, as especificidades da formação do espaço e da sociedade colonial nas regiões de fronteira aberta, com limites políticos ainda não definidos.

\section{A fronteira do Rio Grande}

\section{A situação anterior a 1763}

Desde os anos iniciais da ocupação portuguesa no Presídio do Rio Grande constata-se a presença de um significativo contingente espanhol na região. As rivalidades luso-hispânicas estavam longe de corresponder às dimensões que lhe tem sido dadas pela historiografia regional, sendo que a cooperação entre portugueses e espanhóis no comércio de gado parece ter sido constante. Já em 1723 , antes da existência de qualquer povoação portuguesa no Continente do Rio Grande, os tropeiros espanhóis (neste caso oriundos de Santa Fé) procuravam estabelecer relações comerciais com a vila de Laguna, diante das dificuldades existentes no co-

\footnotetext{
O melhor representante desta historiografia tradicional, no que tange ao período analisado, é: MONTEIRO, Jonathas da Costa Rego. A Dominação Espanhola no Rio Grande do Sul (1763-1777). Rio de Janeiro: Instituto Histórico e Geográfico Brasileiro/Instituto de Geografia e História Militar do Brasil, 1979. Nesta obra, originalmente publicada em 1936, o autor reforça a noção da fronteira excludente já desenvolvida por outros autores desde o final do século XIX.
} 
mércio com a Colônia de Sacramento, em virtude dos empecilhos colocados pela Guarda espanhola de San Juan.

No caso da povoação do Rio Grande, o contingente hispânico era formado principalmente por peões espanhóis, procedentes na sua maioria, de Santa Fé, Corrientes, Entre Rios e Paraguai, exercendo suas atividades nas estâncias reais (como Isidro Maciel, "homem espanhol e domador na Estância de Bojuru") e particulares (era o caso de João Marinho, "peão espanhol na estância de Manuel Jorge"). Esses homens representavam mão-de-obra altamente especializada, de importância vital para a sobrevivência econômica da nova povoação. No caso das atividades que exerciam (cavalariços, boieiros, carreiros, domadores e laçadores) era impossível contar com os elementos portugueses ou africanos, inábeis na atividade pecuária. ${ }^{3}$

Nos inícios da década de sessenta do século XVIII, a freguesia do Rio Grande apresentava uma convivência aparentemente tranqüila entre luso-brasileiros e espanhóis. Os registros de óbitos e batismos deste período (1760-63) confirmam a presença da peonagem de origem espanhola: assim, por exemplo, o caso do peão Baltazar Antunes, natural de Corrientes, solteiro, com cerca de trinta anos, que foi sepultado sem sacramentos, "por morrer na Estância de Antônio Moniz vindo de Chuy para esta vila". Os registros de batismos entre 1760 e 1761 corroboram os argumentos favoráveis a uma coexistência luso-espanhola, indicando a existência de pelo menos nove espanhóis integrados à freguesia (quatro santafesinos, dois paraguaios, um buenaierense, um indicado como sendo das "Índias de Espanha" e um espanhol metropolitano). Estes indivíduos, todos homens, integram-se à nascente sociedade rio-grandina preferencialmente pela via dos casamentos com mulheres açorianas. Cinco dos espanhóis citados casam-se com mulheres das Ilhas enquanto os outros três tem filhos ilegítimos com mulheres indígenas (geralmente de etnia tape). Somente o espanhol José Pinto Lensinha (ou Lencina), que batizou a sua filha na Fortaleza de São Miguel era casado com uma mulher indígena, natural da freguesia de São Pedro do Rio Grande. ${ }^{4}$

QUEIROZ, Maria Luiza B. A Vila do Rio Grande de São Pedro (1737-1822). Rio Grande, Ed. da FURG, 1987, p. 56-57. Os exemplos entre parênteses - citados pela autora são provenientes do $1^{2}$ Livro de Óbitos de Rio Grande (1738-1763), fls. 27 e 30 . Provavelmente são da década de 1740 .

4 IHGRGS/AMD n $35-1^{\circ}$ Livro de Óbitos de Rio Grande (1738-1763), fl. 107 \& AMD $\mathrm{n}^{2} 28-4^{2}$ Livro de Batizados de Rio Grande, fls.20, 32, 38, 47v, 61v, 71, 108 e $113 \mathrm{v}$. 


\section{A situação durante a Dominação Espanhola}

Com a anulação do Tratado de Madri em 1761, devido à assinatura do Tratado de El Pardo, recomeçam as animosidades entre as Coroas ibéricas no extremo sul da América. A deterioração do relacionamento entre Portugal e Espanha deveu-se principalmente à insistência da Coroa lusitana em manter o enclave da Colônia do Sacramento e as possessões sul-rio-grandenses, além do fato de Portugal abandonar a sua política de "neutralidade", ao não aderir ao $3^{\circ}$ Pacto de Família (Espanha, França, Nápoles e Parma), idealizado para combater a política expansionista inglesa. ${ }^{5}$

Em abril de 1763, as forças espanholas lideradas por D. Pedro de Cevallos ocupam militarmente a vila de Rio Grande, dentro de um contexto marcado pelas novas condições internacionais decorrentes da Guerra dos Sete Anos, conflito envolvendo a França e a Inglaterra, que acabou envolvendo os respectivos aliados, Espanha e Portugal. O comandante espanhol, em campanha fulminante, apossou-se da Colônia do Sacramento, dos fortes de São Miguel e Santa Tereza, além de ocupar a própria sede do poder português no Continente, o Rio Grande de São Pedro.

Lamentavelmente, não dispomos dos registros paroquiais de Rio Grande durante o período da Dominação Espanhola. Com a ocupação espanhola de Rio Grande, foram suspensos os registros por parte dos párocos portugueses, já que praticamente $80 \%$ dos seus habitantes haviam fugido para a parte norte do canal (atualmente São José do Norte). ${ }^{\complement}$ A população lusitana que permaneceu na freguesia ocupada, bem como os espanhóis ocupantes devem ter tido os seus registros próprios, realizados por párocos castelhanos, que supostamente levaram os livros consigo quando da retirada espanhola em 1776 . Em compensação, dispomos dos livros das paróquias de Estreito (fundada em 1761, a partir do aldeamento indígena ali existente desde 1753) e Mostardas (fundada em 1773).

$\mathrm{Na}$ freguesia de Estreito, que perdeu suas características de povoado indígena com a "invasão" da população fugida de Rio Grande, encontramos somente dez registros de espanhóis durante o período 1763-1778, sendo notável a ausência da peonagem referida para o período anterior. Com efeito, é possível supor que a pequena população de origem hispânica existente na freguesia de Rio Grande tenha optado em nela permanecer, exercendo as mes- 
mas atividades, agora nas terras ocupadas pelos súditos espanhóis. Dos nomes encontrados nos livros de Rio Grande, só reencontramos um, novamente o já citado José Pinto Lencinha (Lencina), natural de Santa Fé, denominado "espanhol de nação".?

Os registros iniciais da freguesia mostram, no entanto, uma certa convivência entre espanhóis e portugueses. Assim, em setembro de 1763 era batizada Maria, filha de um casal açoriano, "na Estância do Tesoureiro pelo Padre Frei Pedro de Arraiola, franciscano espanhol, em tempo que ali estavam os castelhanos". Um dos padrinhos era o capitão castelhano Francisco Pera. Poucos meses depois, em fevereiro de 1764, "neste Acampamento da Fronteira", batizava seu filho o espanhol Antônio Gomes Parabé, casado com Francisca Maria, natural do Rio de Janeiro. ${ }^{8}$

Em Mostardas, freguesia isolada e pobre, encontramos, no período que vai de 1775 a 1778 o reduzido número de seis registros no primeiro livro de batismos. Na verdade encontramos, com certeza, somente dois espanhóis, o já mencionado José Pinto Lencina (em um registro de 1775) e Antônio Manuel Gomes, natural do Paraguai. Os demais registros referem-se a descendentes da segunda geração de espanhóis, como no caso do também paraguaio José Castro de Antiqueira, que aparece em dois registros como avô materno.'

Se os registros paroquiais chamam a atenção para a existência de espanhóis (ou seus descendentes) nas freguesias portuguesas durante o período da Dominação Espanhola, também é constatável a presença de lusitanos no Rio Grande ocupado pelos espanhóis. Analisando especificamente o caso da freguesia de Rio Grande, chama a atenção o fato de que sendo pobres a maioria dos habitantes de origem açoriana, não tiveram eles condições de transpor, na sua totalidade, o canal, quando da invasão espanhola. Teriam permanecido nos novos domínios castelhanos cerca de 140 familias açorianas, embora o esquema de segurança adotado pelos

IHGRGS/AMD $\mathrm{n}^{\mathrm{g}} 01-1^{\circ}$ Livro de Batizados (1763-1779), fl. 59v. Desconhecemos o significado exato da expressão "espanhol de nação", que eventualmente aparece nos registros. Talvez seja uma referência a uma possível origem indígena, visto a grande presença de populações autóctones nas províncias mesopotâmicas. O fato é que a palavra "espanhol ou castelhano designava tanto o índio proveniente da Missões, como de Corrientes, do Paraguai, de Buenos Aires ou o elemento natural da própria Espanha, ou ainda o americano de origem ibérica" (Cf. FERRAZ, J. M. Os primeiros gaúchos da América Portuguesa. Porto Alegre, IEL/UCS, 1980, p. 9-10).

IHGRGS/AMD n²01 - 1² Livro de Batizados de Estreito (1763-1779), fl. 26.

IHGRGS/AMD n² 04-1² Livro de Batizados de Mostardas (1773-1806), fls. 5, 6, 17 e $20 \mathrm{v}$, 
ocupantes não permitisse a permanência desta população no centro da Vila. Formaram-se, consequentemente, quatro núcleos de colonos lusos nas imediações da vila do Rio Grande, a saber: Torotama (depois denominado de Povo Novo), o núcleo dos "Paulistas", o núcleo do Saco da Mangueira e o núcleo dos Carreiros. Posteriormente, estes núcleos populacionais foram aumentados, com a vinda de famílias espanholas, e com o casamento dos filhos dessas com filhos de familias portuguesas. Segundo Queiroz, " o que se evidencia, [...] é que a convivência de portugueses e espanhóis no Rio Grande ocupado transcorreu em clima predominante de harmonia e de colaboração mútua. $\mathrm{O}$ governo espanhol manteve uma política incomum, abrindo mão da cobrança de direitos ou tributos dos portugueses durante todo o período da dominação, e indenizando pontualmente, e a preço justo, o seu fornecimento de gêneros, tratamento que, sem dúvida, os casais açorianos não haviam recebido ainda da administração portuguesa". ${ }^{10}$

Assim, neste Rio Grande bipartido, o lado espanhol parecia ser aos povoadores açorianos mais promissor do que o próprio lado português. Isto explicaria a permanência de muitos moradores portugueses nos territórios espanhóis e contraria frontalmente a representação idealizada que procura constituir uma total exclusão na região fronteiriça em disputa pelas metrópoles ibéricas.

\section{Os campos de Viamão}

Se a convivência entre portugueses e espanhóis na "fronteira do Rio Grande" aparentemente foi de alguma forma abalada (mas não impossibilitada) com a ocupação militar castelhana, na região dos denominados "Campos de Viamão" a situação parece ter sido um pouco diversa. " Esta região, os imprecisamente chamados

${ }^{10}$ Queiroz, op. cit., p.117, 118 e 120. Outras fontes contemporâneas confirmam a convivência luso-espanhola no Rio Grande ocupado: "Alguns portugueses, que não puderam fugir aos inimigos, foram enviados por estes para Maldonado, Còrdova, Mendoza, etc., e alguns permaneceram na mesma habitação entre os mesmos inimigos, até verem como estes fugiram aos portugueses" (Cf. FERNANDES, Domingos José Marques. Descrição Corográfica, Política, Civil e Militar da Capitania do Rio Grande do São Pedro do Sul (1804). In: Pesquisas - História, n² 15, Porto Alegre: Instituto Anchietano de Pesquisas, 1961, p. 34).

11 A importância do povoamento hispânico no Rio Grande do Sul colonial já havia sido reconhecida: "Os espanhóis não competem nem de longe em número com os elementos do mundo luso-brasileiro, mas sua contribuição foi considerável. Eram geralmente pessoas avulsas, que aqui casaram com mulheres brancas ou pardas e constituíram suas familias, algumas delas muito numerosas e com vasta descendência" 
Campos de Viamão, abrangia uma imensa área, no nordeste do atual RS. Os tais campos corresponderiam às terras situadas ao sul do rio Mampituba, tendo ao leste o Oceano Atlântico, e a oeste e a sul a baliza fluvial do Guaíba e da Lagoa dos Patos. Para os paulistas e lagunistas que exploraram o Rio Grande a partir do "Caminho da Praia", os campos eram todas as planícies despovoadas à margem esquerda do Rio de São Pedro. ${ }^{12}$ Posteriormente, com o desenvolvimento populacional, será criada a freguesia de Viamão (1747), desmembrada de Laguna. A freguesia de Viamão deu origem, nas décadas seguintes, a diversas outras freguesias, como Triunfo (1756), Rio Pardo (1762), Santo Antônio (1763), Taquari (1765) e Porto Alegre (1772), entre outras.

Foram motivações econômicas, derivadas da descoberta e exploração das Minas Gerais, especialmente as necessidades de abastecimento e transportes, que provocaram a integração do Sul ao mercado interno colonial. A grande atração dos campos de Viamão consistia, como é sabido, nas grandes reservas de gado bovino e muar que aqui podiam ser adquiridas e comercializadas no centro do Brasil. O capitão-general de São Paulo ordenou em 1727 a abertura da estrada de Laguna que, ligando os campos do Rio Grande aos de Curitiba, possibilitaria a subida das tropas de gado. Com a abertura do Caminho dos Conventos, "Laguna se tornou um centro de comércio clandestino com espanhóis renegados que buscavam o gado na Vacaria del Mar. A abertura da estrada através do planalto para São Paulo via Curitiba e Sorocaba (1727-1732) possibilitou à capitania a fornecer bovinos, eqüinos e muares para as comunidades urbanas mineradoras de Minas Gerais". ${ }^{13}$

Iniciava-se assim, com a atividade dos tropeiros, a integração dos campos de Viamão com as regiões mineradoras do sudeste colonial. Em 1731 Cristóvão Pereira de Abreu realizou a primeira passagem de tropas, dando início a um lucrativo comércio, que levou a Coroa a organizar o fisco com a criação dos Registros de Curitiba

(Cf. NEIS, Ruben. Guarda Velha de Viamão. Porto Alegre: EST/Sulina, 1975, p. 66). No entanto, este autor simplesmente faz um arrolamento de nomes de indivíduos, não se preocupando em tentar desvelar as relações socioeconômicas mantidas por estes homens nos campos de Viamão. Neis os denomina como sendo "ibéricos" e "castelhanos": os primeiros seriam os naturais da península Ibérica, enquanto que os outros seriam naturais da América. Esta terminologia nos pareceu inapropriada, por isso nos referimos a espanhóis (europeus) e a hispano-americanos.

12 CÉSAR, Guilhermino. História do Rio Grande do Sul-Periodo Colonial. Porto Alegre: Globo, 1970, p. 88.

13 ALDEN, Dauril. Royal Government in colonial Brazil, with special reference to the administration of the Marquis of Lavradio, Viceroy (1769-1779). Berkeley \& Los Angeles, University of California Press, 1968, p. 72. 
e Sorocaba em 1743. Possivelmente por esta época (ou alguns anos antes) também foi criado o Registro de Viamão, originário de uma guarda militar criada em 1737, a "guarda velha" de Viamão, situada próxima à atual Santo Antônio da Patrulha. ${ }^{14} \mathrm{O}$ Registro de Viamão foi constituído a partir da abertura do Caminho do Sertão, provavelmente entre 1735 e 1740, ligando os campos de Viamão ao caminho aberto por Sousa Faria em 1728. Desta forma, o gado sulino, partindo de Viamão, passava por uma série de registros (Viamão, Curitiba e Sorocaba) até chegar ao seu consumidor final, no caso, as populações das regiões mineradoras. Posteriormente, nos inícios da década de 1770, a Coroa criou também o Registro de Santa Vitória, próximo a atual cidade de Bom Jesus, nas margens do rio Pelotas, limite norte do Rio Grande de São Pedro com a Capitania de São Paulo.

Quanto ao volume deste comércio, não temos dados seguros, apenas algumas indicações. A partir de 1733, ou pouco depois, é que começa a se avolumar o número de bestas muares vindas do Sul para São Paulo, geralmente de passagem para a região mineradora. Segundo um livro de registros da vila de Parnaíba (SP), em 1754, um tropeiro castelhano, Bartolomeu Chevar, conduziu dos campos rio-grandenses para as Minas Gerais 3780 cabeças de muares, que teriam rendido para o tesouro real 5:021\$000 de impostos. ${ }^{15}$

É possível fazer-se uma estimativa precária, a partir dos contratos dos arrematadores dos registros sulinos. De acordo com uma tradicional prática das monarquias do Antigo Regime europeu, que foi transportada para as colônias, estabeleciam-se contratos entre a Coroa e particulares, pelos quais a primeira transferia para os segundos a prerrogativa de cobrar impostos. O lucro do arrematante tratava-se do excedente do valor do imposto para além da quantia inicialmente estipulada com o Estado. Adicionalmente, caso o arrematante fosse um negociante, poderia auferir vantagens diante de sua posição monopolista no mercado. ${ }^{16}$ Se-

${ }^{14}$ WESTPHALEN, Cecilia Maria. Verbetes "Tropas" e "Caminho do Viamão" In: SILVA, Maria Beatriz Nizza da (coord.). Dicionário da História da Colonização Portuguesa no Brasil. Lisboa: Verbo, 1994, p. 802 e 827. Sobre o Registro de Viamão ver: JACOBUS, André Luís. "Registro de Viamão: novos aportes históricos e arqueológicos". In: SANTOS, Lucila M. S. (org.). Bom Jesus e o tropeirismo no Brasil Meridional. Porto Alegre, EST, 1995, p. 122-123.

15 HOLANDA, Sérgio Buarque de. Caminhos e Fronteiras. 3. ed. São Paulo, Companhia das Letras, 1994, p. 130.

${ }^{16}$ FRAGOSO, João Luís. Homens de Grossa Aventura. Rio de Janeiro: Civilização Brasileira, 1998, p. 326-327. Segundo este autor, "através da arrematação de impostos, o 
gundo os dados levantados, referentes a Viamão, salvo qualquer possível erro, parece que o auge da atividade de comércio de gado situou-se por volta de meados da década de cinqüenta do século XVIII. ${ }^{17}$ (ver tabela 1 ).

Tabela 1. Contratos de arrematação dos registros sulinos (século XVIII)

\begin{tabular}{|c|c|c|c|}
\hline Triênio & $\begin{array}{l}\text { Nome do } \\
\text { arrematante }\end{array}$ & Valor do contrato & Observações \\
\hline $1752-1754$ & Manoel Cordeiro & 7.205 .000 réis/ano & \\
\hline $1754-1756$ & $\begin{array}{l}\text { Caetano Diogo } \\
\text { Parreiras }\end{array}$ & 13.615 .000 réis/ano & \\
\hline $1762-1765$ & $\begin{array}{l}\text { Custódio Barroso } \\
\text { Basto }\end{array}$ & 5.333 .333 réis/triênio & \\
\hline $1770-1772$ & $\begin{array}{l}\text { Bernardo Gomes } \\
\text { da Costa }\end{array}$ & 5.333 .333 réis/triênio & $\begin{array}{l}\text { Era comerciante no } \\
\text { Rio de Janeiro }\end{array}$ \\
\hline $1773-1775$ & $\begin{array}{l}\text { Bernardo Gomes } \\
\text { da Costa (com } \\
\text { sócios) }\end{array}$ & 10.000 .000 réis/triênio & $\begin{array}{l}\text { Incluídos os direitos } \\
\text { do Registro de } \\
\text { Santa Vitória }\end{array}$ \\
\hline $1782-1784$ & $\begin{array}{l}\text { Capitão Manoel } \\
\text { de Araújo Gomes }\end{array}$ & 10.225 .000 réis/triênio & idem \\
\hline
\end{tabular}

A sensível diminuição dos valores dos contratos, a partir da década de 1760, pode estar relacionada, por um lado, à perda do dinamismo econômico das regiões mineradoras, que constituíam os principais mercados consumidores, em função do decréscimo da produção aurífera ${ }^{18}$; por outro lado, pode também refletir a conjuntura relativamente desfavorável ao comércio de gado, em função dos conflitos armados (1763-1776) no Continente.

negociante colonial inverte os papéis, presentes no Pacto Colonial, desempenhados pelo colonial e pelo metropolitano. Se a cobrança de impostos era, em princípio, um dos mecanismos pelos quais o excedente colonial seria transferido para a Metrópole, quando esses impostos passam a ser cobrados por coloniais, tais pressupostos são pervertidos. Este excedente deixa de ser, em parte, remetido para a Metrópole, passando, assim, a alimentar uma acumulação mercantil interna à Colônia" (p. 329).

As fontes das informações acima reproduzidas são: Jacobus, loc. cit. p. 125-126 e FLORES, Moacyr. "O tropeirismo e a economia colonial" In: SANTOS, Lucila M. S. (org.). Bom Jesus e o tropeirismo no Brasil Meridional. Porto Alegre: EST, 1995, p. 145 , 147 e 148.

15 Ao analisar a crise da mineração verificada a partir de 1760 , Wehling faz a seguinte observação: "Um bom termômetro da atividade econômica eram os registros nas passagens dos rios, pois controlavam as entradas da capitania [de MG]. O do rio das Mortes teve seu rendimento reduzido de seis para três contos de réis entre 1756 e 1776; o do rio Grande, de 1,5 conto para 400 mil-réis" (WEHLING, Arno. Formação do Brasil Colonial. Rio de Janeiro: 1994, p. 321). 


\section{Os campos de Viamão antes de 1763}

Os registros paroquiais da freguesia de Viamão revelam uma expressiva presença de espanhóis no período anterior à Dominação Espanhola, sendo que o primeiro livro de batismos (1747-1759) chega a contar com mais de $10 \%$ dos seus registros referentes a indivíduos de origem hispânica (entre metropolitanos, criollos, mestiços e indígenas). Nos termos consultados, encontramos 19 diferentes nomes, sendo oito de origem metropolitana (castelhanos, galegos, andaluzes e valencianos) e onze de origem americana, também de diversas procedências (Corrientes, Santa Fé, Córdoba, Santiago, Tucumán, Salta, Buenos Aires e Paraguai/Assunción).

A superioridade numérica dos hispano-americanos não é surpreendente, pois uma análise mais detida dos fluxos regionais de mercadorias no espaço platino indica claramente a relevância econômica das povoações espanholas acima citadas. Não deveria pois se estranhar a presença de indivíduos originários destas localidades, muitas delas situadas no "caminho do Peru". Deixando de lado a cidade de Buenos Aires, detenhamo-nos por um momento nestes fluxos regionais voltados para o mercado interno colonial. No caso da vila de Corrientes, sua principal atividade econômica era a intermediação de mercadorias entre Assunción e Santa Fé: os correntinos adquiriam a erva-mate paraguaia, vendendo-a aos santafesinos e também vendiam o gado alçado (oriundo do Chaco boreal ou das possessões jesuíticas) aos paraguaios. Secundariamente se desenvolveu a exploração madeireira, visando a construção de barcas e carretas. Em Santa Fé, serão três as principais atividades econômicas: era um importante entreposto no comércio com o Paraguai, negociando erva, tabaco e açúcar; também destacava-se o tráfico de gado bovino e muar, vendido para a região de Potosi; finalmente, a cidade lucrava com a atividade de fretes (carreteiros) e aluguéis de casas e armazéns. Outra vila importante era Córdoba, situada no centro dos caminhos que levavam ao Peru. Esta cidade se destacará durante as três primeiras três décadas do século XVII pela sua produção de têxteis de algodão; a partir de 1630, com a decadência da atividade têxtil, inicia-se a criação de mulas e gado vacum, para venda nos mercados alto-peruanos. No caso de Santiago, podemos nos referir a duas povoações distintas: uma delas é Santiago del Estero, região que contava com uma pequena produção própria de gado bovino e muar; a outra é Santiago do "Reino do Chile", fornecedora de vinhos, frutas secas e tecidos. Tucumán era uma região fornecedora de madeiras duras, próprias para a construção de carretas, ao passo que Salta era conhe- 
cida por sua grande feira de mulas ( 40 mil animais por ano, no final do século XVII) e seus excelentes "potreros de invernada". ${ }^{19}$

Considerando-se as atividades econômicas exercidas por estas cidades, compreendemos perfeitamente a presença destes indivíduos nos campos de Viamão, atuando como tropeiros e carreteiros. Esta reorientação dos fluxos comerciais está associada à nova conjuntura verificada a partir das primeiras décadas do século XVIII. Por um lado, temos o agravamento da crise potosina, ao mesmo tempo que verifica-se o início da exploração aurífera na região das Minas Gerais. Por outro lado, a partir de 1715 iniciam as grandes "invasões" indígenas que desarticulam as vias comerciais ligando Santa Fé, Córdoba, Corrientes e o Paraguai. Assim, uma dupla motivação teria animado estes hispano-americanos a migrarem para as terras portuguesas: a atração econômica de uma região dinâmica, necessitada de animais de carga e as conseqüências da resistência indígena ao avanço colonizador, que impediria o uso das vias comerciais usuais. ${ }^{20}$

Infelizmente, os registros são lacônicos no que se refere às ocupações destes espanhóis e hispano-americanos. Em alguns casos, é possível inferir um envolvimento com a atividade tropeira: devia ser esta a função de Pedro Fernandes, natural das "Índias de Espanha" e de Sebastião Gomes, natural de "Santiago de Buenos Aires". Ambos aparecem nos registros, durante o ano de 1748, relacionados a Manuel de Barros Pereira, que foi um dos primeiros tropeiros do Continente, afazendando-se próximo à atual Lagoa dos Barros. Quanto aos espanhóis, Fernandes casou-se com Teresa Tapanhuna, natural da Costa da Mina, escrava de Manuel de Barros, enquanto que Gomes casou-se com uma índia "tape forra", tendo o próprio Barros como padrinho. ${ }^{21}$

No entanto, a maioria dos espanhóis parece ter optado pelas mulheres lagunenses, visto que dos 17 indivíduos casados, nove o são com mulheres originárias de Laguna. Esta "preferência" pode estar associada a uma migração destes indivíduos de Laguna para os campos de Viamão, especialmente a partir da década de 1740 , com a diminuição da importância econômica da vila catarinense,

19 GARAVAGLiA, Juan Carlos. Mercado interno y economía colonial. México, DF: Grijalbo, 1983 , p. $397-404$

Garavaglia, op. cit. p. 399-400.

${ }^{21}$ IHGRGS/AMD n² $62-1^{2}$ Livro de Batizados de Viamão (1747-1759), fls. 5v-6. Quanto ao uso do termo "tapanhuno", refere-se à denominação usual dada pelos paulistas aos "negros da Guiné", ou seja, os escravos africanos. Já o significado da expressão "tape forra" guarda certa ambigüidade: poderia se referir a uma ex-escrava indígena ou ainda a uma índia livre, sendo forro sinônimo de livre. Sobre estas questões, ver: MONTEIRO, John. Negros da Terra. São Paulo: Companhia das Letras, 1994. 
em função da concentração do comércio ganadeiro pelo Caminho de Viamão. Em um registro de 1756 aparece o caso do correntino José dos Santos, casado com Narcisa Pedrosa, cujos pais, Custódio Pedroso e Maria Dias eram naturais da vila de Laguna "e agora moradores todos desta freguesia nos campos junto à guarda de Viamão". ${ }^{22}$

No período imediatamente anterior (1759-1763) à ocupação militar espanhola do Continente do Rio Grande, a freguesia de Viamão continuava apresentando um número relativamente elevado de registros de espanhóis ou seus descendentes diretos: dos 111 registros de batismos feitos entre março de 1759 e agosto de 1763, nada menos do que 21 referem-se a pessoas de origem hispânica. Além dos nomes que já apareciam no período anterior (1747-1758), como os de Agostinho Guterres ${ }^{23}$, Pedro d'Ávila e Pedro José Caro, surgem alguns novos, como os de José Inácio Medina e Lourenço da Veiga, naturais de Corrientes. É impossível precisar exatamente qual a proporção existente entre hispânicos, lusitanos e indígenas na freguesia de Viamão. Novamente, só podemos fazer estimativas, a partir dos precários dados demográficos disponíveis: segundo os registros do Juízo Eclesiástico de Viamão, a paróquia teria, em 1760, um total de 152 fogos (casas), com 906 moradores adultos. ${ }^{24}$ Deve-se salientar que este número não incluía as crianças (até sete anos), bem como uma quantidade variável (e incomputável) da população de origem africana e indígena.

Considerando que os registros paroquiais do período 17471763 captaram apenas uma parcela da população hispânica existente na freguesia de Viamão, é possível supor a presença de uma significativa minoria hispânica ou hispano-americana dentro de territórios pretensamente portugueses. Nota-se que os registros de batismos detectam somente aquela parte da população efetivamente integrada à vida paroquial, sem levar em consideração outra parcela de indivíduos, que pela sua transitoriedade, não foram capturados pelos termos eclesiásticos. De qualquer modo, fica

${ }^{22}$ IHGRGS/AMD n ${ }^{2} 62-1^{2}$ Livro de Batizados de Viamão (1747-1759), fl. 73v.

${ }^{23}$ O valenciano Agostinho Guterrez era casado com Maria, filha de Francisco de Brito Peixoto, um dos fundadores da vila de Laguna no final do século XVII. Apesar de sua origem hispânica, Guterrez foi vereador na Câmara de Laguna em 1723, tendo se mudado, um decênio mais tarde, para os campos de Viamão. Cf. CABRAL, Oswaldo R. "Notas históricas sobre a fundação da póvoa de Santo Antônio dos Anjos da Laguna", in: Santo Antônio dos Anjos da Laguna: seus valores históricos e humanos. Florianópolis: Imprensa Oficial do Estado de SC, 1976, p. 60.

${ }^{24}$ IHGRGS/AMD n $n^{9} 63-2^{9}$ Livro de Batizados de Viamão (1759-1769), fls. 01-28. Os dados populacionais são referidos por Neis, op.cit., p. 145. 
patente a expressiva participação de indivíduos de origem espanhola na população de Viamão, o que põe por terra qualquer tese defensora do "povoamento homogêneo" lusitano desta região.

\section{Viamão, Triunfo e Rio Pardo após 1763}

Em junho de 1763, o Marquês de Valdelírios (ex-comissário chefe espanhol do Tratado de Madri, nesta altura membro do Conselho de Estado do governo do rei Carlos III), em resposta a uma consulta do Ministro da Guerra, Julián de Arriaga, analisava o significado da ocupação portuguesa do Rio Grande. Na sua análise, Valdelírios afirmava que o interesse português na região começara com a abertura do caminho dos Conventos, ligando o sul de Santa Catarina com São Paulo. Esta estrada, na sua opinião, fora aberta para facilitar o comércio ilegal de gado pertencente à Espanha. Os bovinos e muares eram retirados das estâncias existentes ao redor de Montevidéu, Santa Fé e Corrientes por "ladrões", que os trocavam por tecidos e aguardente fornecidos pelos portugueses.

Logo em seguida, os portugueses ocuparam o Rio Grande e estabeleceram estâncias, protegendo-as com fortificações, no sentido de ficarem em uma melhor posição para explorar as reservas de gado da Espanha. Algumas das fortificações chaves, notadamente São Miguel e Jesus-Maria-José (Rio Pardo), eram na verdade portões de entrada para os animais fornecidos pelos renegados espanhóis, que os retiravam das pastagens naturais existentes na Banda Oriental e das estâncias das missões jesuítas. Segundo o marquês, todos os estabelecimentos portugueses no Rio Grande eram contrários aos tratados de 1494 e 1761, sendo altamente recomendável que os lusitanos fossem expulsos, senão a Espanha continuaria a ter sérias perdas nas suas reservas de gado. ${ }^{2}$

Embora a Coroa espanhola não tenha conseguido expulsar os portugueses do Rio Grande, parece que conseguiu restringir, de certa forma, o comércio ilegal de gado, que vicejou durante a décadas de 1740-50. É isso que se depreende da análise dos livros paroquiais de Viamão, Triunfo e, em menor medida, de Rio Pardo. Nestes livros, escasseia a presença de novos indivíduos de origem espanhola, o que constitui-se num possível reflexo de uma política mais efetiva de combate ao contrabando pelas autoridades espanholas.

${ }^{25}$ Campaña del Brasil - Antecedentes Coloniales, tomo 3, p. 89-92, citado por Alden, op. cit., p. 101-102. 
Na freguesia de Viamão, os registros de batismo, no período 1764-1776, indicam uma retração no fluxo populacional de origem espanhola, pois somente três novos indivíduos batizam seus filhos na paróquia: Manuel [ilegível], natural de Córdoba; José [ilegível], natural da Espanha e Paulo Soares, natural de Santiago del Estero. Nos demais registros, os espanhóis aparecem na condição de avós maternos ou paternos, o que nos impossibilita afirmar a sua efetiva presença na freguesia.

Talvez o "desaparecimento" destes espanhóis nos registros paroquiais seja o reflexo da política restritiva ao comércio de muares, praticada pela Coroa portuguesa entre 1765 e 1769. Através da Carta Régia de 24.12.1764, ficava proibida a entrada de machos e mulas no Estado do Brasil, atendendo aos interesses dos criadores de cavalos nordestinos. Esta proibição só foi revogada parcialmente em 1769, liberando a criação de mulas no continente do Rio Grande. Alguns exemplos desta contraditória política podem ser retirados dos registros da Real Fazenda, cuja provedoria fora transferida para Viamão, após a ocupação espanhola de Rio Grande. Em julho de 1768, o espanhol Manoel Munhoz chegou a Rio Pardo com uma tropa de mais de mil cabeças de gado, entre eqüinos e muares. Todos os animais foram confiscados pelas autoridades portuguesas de Rio Pardo. Inconformado, o espanhol viajou a Viamão, dirigindo uma petição ao governador Sá e Faria, alegando que ignorava a proibição de entrada de muares e se sentia injustiçado pelo confisco. O governador não atendeu aos seus reclamos, em nome do combate ao contrabando. Poucos meses depois, no entanto, o espanhol Eugênio Barragan, trazendo uma tropa de quase quinhentas cabeças de gado (400 éguas, 80 potros, 5 burreiros, 6 echores e 2 burras) solicitou licença para se estabelecer em algum lugar dos domínios portugueses com criação de animais cavalares e muares. Em setembro de 1768, o governador despachou favoravelmente para a instalação da fazenda nos campos de Viamão. ${ }^{27}$ Efetivamente, o que se verifica é que em nenhum momento as proibições foram tomadas ao pé da letra, pois embora o contrabando fosse a princípio combatido, dependendo da situação havia uma certa flexibilidade das autoridades coloniais portuguesas, ciosas dos direitos vultuosos a serem pagos nos registros estabelecidos no Continente.

${ }^{26}$ IHGRGS/AMD n² $63-2^{2}$ Livro de Batizados de Viamão (1759-1769), fls. 28-133v \& $n^{2} 64-3^{\circ}$ Livro de Batizados de Viamão (1769-1782), fls. 2v, 20v e 75.

27 AHRS - Livro de Registros da Real Fazenda - $n^{2} 163$, fls. 153-153v e 163-164. Exemplos citados por Flores, loc. cit., p. 139. 
A partir de 1757, a freguesia de Viamão vê-se desmembrada de uma considerável parte, que constituirá a freguesia de Triunfo. A ocupação das terras da futura freguesia iniciou-se dez anos antes, ou seja em 1747, quando ocorreu a chegada de Manoel Gonçalves Meirelles e sua família nos campos da sesmaria da Piedade, cuja doação foi efetivada em 20.10.1754. Meirelles era natural de Mondim do Basto, arcebispado de Braga, no extremo norte de Portugal, região de fronteira com a Espanha. Casou-se, no Brasil, com Antonia da Costa Barbosa, natural de Guaratinguetá (SP). ${ }^{28}$

Nesta pequena freguesia, o pároco responsável, o Pe. Thomaz José Clarque (que dirigiu a freguesia entre 25.03.1757 e 14.02.1779) seguiu mais de perto as normas eclesiásticas, geralmente desrespeitadas, dividindo a população conforme a sua cor/condição. Assim, dispomos de dois livros distintos de batismos: um para a população branca e livre e outro para os escravos, pardos (livres ou não) e índios. Nestes dois livros, entre os anos de 1763 e 1776, encontramos 22 registros, evidenciando um total de sete indivíduos de origem espanhola (ver tabelas 2 e 3).

Tabela 2. TRIUNFO $-1^{\circ}$ de Batizados -Livres (1757-1786).

\begin{tabular}{|l|l|l|l|}
\hline Data: & Nome: & Origem: & Condição: \\
\hline 29.08 .63 & João Gonçalves Salgado & Galiza & pai \\
\hline 08.09 .65 & idem & idem & idem \\
\hline 24.05 .67 & idem & idem & idem \\
\hline 09.04 .69 & idem & idem & idem \\
\hline 04.06 .69 & Pedro Gonçalves Sotto & Galiza & pai \\
\hline 03.11 .69 & Bernardo Baquedano & Índias de Espanha & avô materno \\
\hline 29.04 .70 & João Piza & Castela & avô materno \\
\hline 02.09.70 & Pedro Gonçalves Sotto & Galiza & pai \\
\hline 28.11 .71 & Bernardo Baquedano & Índias de Espanha & avô materno \\
\hline 30.11 .71 & Martinho Garcia & Castela & avô materno \\
\hline 18.04 .72 & Pedro Gonçalves Sotto & Galiza & pai \\
\hline 26.07 .72 & João Gonçalves Salgado & Galiza & pai \\
\hline 24.08 .73 & Bernardo Baquedano & Índias de Castela & avô materno \\
\hline 03.03 .74 & Pedro Gonçalves Sotto & Galiza & pai \\
\hline 12.06 .74 & Martinho Garcia & Castela & avô materno \\
\hline 31.12 .75 & João Gonçalves Salgado & Galiza & pai \\
\hline 27.05 .76 & Pedro Gonçalves Sotto & Galiza & pai \\
\hline
\end{tabular}

2月 FREITAS, Fernando de Castro. Triunfo - história, gente e legendas. Porto Alegre: Martins Livreiro, 1985, p. 15. 
Tabela 3. TRIUNFO - 1 Livro de Batizados de escravos, pardos e índios (1757-1782)

\begin{tabular}{|l|l|l|l|}
\hline Data: & Nome: & Origem: & Condição: \\
\hline 26.07 .60 & Maria da Luz & $\begin{array}{l}\text { São Domingos das Missões } \\
\text { de Montevidéu }\end{array}$ & mãe \\
\hline 23.01 .63 & idem & idem & idem \\
\hline 01.11 .69 & Manuel (Martinho) Garcia & Reino de Castela & pai \\
\hline 16.01 .72 & Bernardo Baquedano & Índias de Castela & pai \\
\hline 26.06 .72 & José dos Santos, índio & Corrientes & pai \\
\hline
\end{tabular}

Destes sete indivíduos, três tem indubitável origem indígena, como Maria da Luz, natural de São Domingos Soriano ${ }^{29}$ e José dos Santos, que aparece denominado como índio. Este último já aparecia nos livros de Viamão desde 1749 , sendo um dos poucos indivíduos cuja trajetória pode ser acompanhada depois de 1763 . Nos livros de Viamão, omitia-se, no entanto, a sua etnia, o que em Triunfo ficou evidenciado. Um terceiro, Bernardo Baquedano, também deve ser indígena, pois aparece denominado como sendo do "gentio da terra". Curiosamente, os seus netos já são considerados "brancos", enquanto que seu filho é registrado no livro dos "nãobrancos". A segunda geração já integra o grupo de homens livres, passando por um "embranquecimento" social. Baquedano era casado com Bernarda Correia de Sousa, natural de Laguna. Sua filha, Ana Maria Pais de Sousa, nascida em Viamão, casou-se com o paulista Antônio Francisco de Camargo, natural de Taubaté. ${ }^{30}$

Os outros quatro indivíduos eram espanhóis metropolitanos, dois denominados castelhanos (Martinho Garcia e João Piza) e dois galegos (João Gonçalves Salgado e Pedro Gonçalves Sotto). Sobre Garcia pouco sabemos, além do fato de ser casado com uma índia, Maria Pedroso, natural de Laguna. Quanto a João Piza, no primeiro livro de batismos de Viamão, em 1755, aparece como originário da ilha de Maiorca. Passados alguns anos, ele transformou-se em um simples castelhano...

29 Era casada com Lourenço Dorneles, filho natural de Jerônimo de Ornellas com uma índia, Maria Fragoso, natural de Minas Gerais. Ornellas era um dos mais antigos ocupantes dos campos de Viamão, tendo se mudado, com sua família, para Triunfo em 1757. Este filho natural indica que possivelmente ele estivera nas Minas Gerais, talvez na atividade de tropeiro.

30. IHGRGS/AMD n ${ }^{2} 06-1^{2}$ Livro de Batizados de Triunfo (brancos) - 1757-1786, fl. 27 $\& \mathrm{n}^{2} 07-1^{2}$ Livro de Batizados de Triunfo (escravos, pardos e índios) - 1757-1782, fl. $52 \mathrm{v}$. 
Felizmente, temos maiores informações sobre os dois espanhóis originários do Reino da Galiza, região que faz fronteira com o extremo setentrional de Portugal. O primeiro deles a chegar na freguesia, João Gonçalves Salgado, era natural do bispado de Orense, na Galiza, situado a pequena distância do arcebispado de Braga, no norte de Portugal. O seu sogro, José Leite de Oliveira, era natural das Cabeceiras do Basto, arcebispado de Braga, a mesma região do pioneiro desbravador da freguesia, Manuel Gonçalves Meirelles. Devemos atentar para a origem rural destes colonizadores que vieram povoar o Continente, oriundos do extremo setentrional lusitano, onde situava-se o arcebispado de Braga: "Assim, o Norte montanhoso, é, por isso mesmo, grande reservatório de homens, de proletários, [...] região onde freqüentemente reina a fome montanhesa, grande alimentadora das descidas, das constantes emigrações".

Não se trata de mera coincidência, assim pensamos, o fato de que Salgado tenha migrado para esta região específica do Brasil; pelo contrário, supostamente ele deveria ter alguma espécie de referência sobre Triunfo: a proximidade geográfica entre as regiões de origem destes colonos não teria possibilitado alguma informação ou contato prévio? Segundo Faria, "apesar de algumas áreas terem um atrativo especial, a decisão de abandonar o lugar de origem e de escolher determinada região, no século XVIII, se dava, pelo que se pode perceber, por já estarem ali pessoas conhecidas. Em séculos anteriores, provavelmente a aventura do desconhecido era maior, mas mesmo assim, informações prévias e algum conhecimento precediam a decisão de migrar e a opção por determinada área".

Parece ter sido este o caso de Salgado, que deve ter chegado à freguesia de Triunfo antes de 1762, visto que em fevereiro deste ano ele se casou com Ana Maria de Oliveira, filha de José Leite de Oliveira e Fabiana de Ornelas (nascida em 1722, em Guaratinguetá), a primeira filha de Jerônimo de Ornellas. Como já apontamos, o seu sogro provinha de uma região, em Portugal, muito próxima da fronteira com o "Reino da Galiza", então pertencente à Espanha. Assim, o adventício "espanhol", João Gonçalves Salgado, provavelmente já dispunha de informações preliminares acerca da região remota para a qual emigrava. Passados alguns anos, talvez

"MATTOSO, José. Identificação de um país - ensaio sobre as origens de Portugal. Lisboa: Estampa, 1985, p. 29.

32 FARIA, Sheila de Castro. A Colônia em Movimento: fortuna e familia no cotidiano colonial. Rio de Janeiro, Nova Fronteira, 1998, p. 170. 
estabelecido em alguma propriedade (o casamento era acompanhado sempre de um dote), Salgado já comparecia nos registros paroquiais de Triunfo como proprietário de escravos: o Pe. Clarque, em 26.08.1766, assinou o batismo de "Inácia, filha de Felícia, preta solteira escrava de João Gonçalves Salgado e deu por pai Luís Vieira, soldado"."33

Em situação semelhante aparece também o espanhol Pedro Gonçalves Sotto, que talvez fosse parente de Salgado. Tendo chegado em Triunfo antes de 1768, neste mesmo ano ele casou-se com Vicência Maria da Conceição, natural de Rio Grande, filha do tenente Manuel Alves de Carvalho e mãe incógnita. O referido tenente era um dos maiores proprietários de escravos de Triunfo, tendo registrado nove batismos de escravos entre 1757 e 1770. Através destes registros podemos inferir um plantel de no mínimo quinze escravos. Curioso é assinalar que enquanto a freguesia de Triunfo esteve sob os cuidados do Pe. Clarque, Sotto aparece registrando seus filhos nos livros dos homens brancos, sendo que a ascendência materna era sempre omitida (avó incógnita). Todavia, em outubro de 1779 , em um novo registro de batismo, feito no livro dos escravos, pardos e índios, e feito sob os cuidados do sucessor do Pe. Clarque, o espanhol Sotto aparece como sendo casado com "Vicência Maria da Conceição, parda, natural de Rio Grande, [...] filha natural do tenente Manuel Alves de Carvalho e a mãe ignora o nome". Ao casar sua filha bastarda com um espanhol adventício, o tenente Carvalho também contribuiu para o "embranquecimento" social de seus descendentes. ${ }^{34}$

As fontes que consultamos não permitem descrever com exatidão a atividade exercida por estes indivíduos na freguesia de Triunfo. No entanto, a sua vinculação com a escravaria africana permite supor que essa mão-de-obra cativa fosse utilizada na agricultura de gêneros de subsistência. Não podemos afirmar com absoluta certeza, mas possivelmente estes espanhóis/galegos não estivessem vinculados somente à atividade pecuária, como no caso dos "espanhóis de Viamão". 35

33 IHGRGS/AMD n ${ }^{2} 15-1^{2}$ Livro de Casamentos de Triunfo (1757-1794), fl. 10 \& $n^{2} n^{2}$ $07-1^{2}$ Livro de Batizados de escravos, pardos e índios de Triunfo (1757-1782), fl. $27 v$.

${ }^{34}$ IHGRGS/AMD n⿳0 $15-1^{9}$ Livro de Casamentos de Triunfo (1757-1794), fl. 26 \& $\mathrm{n}^{0} \mathrm{n}^{2}$ $07-1^{2}$ Livro de Batizados de escravos, pardos e índios de Triunfo (1757-1782), fl. $102 v$.

35 Segundo os dados de um levantamento populacional feito em 1780, a freguesia de Triunfo tinha 1277 habitantes. Destes, 640 eram "pretos" e 637 eram "brancos". Cf. SANTOS, Corcino Medeiros dos. Economia e sociedade do Rio Grande do Sul - século 
Finalmente, na freguesia de Rio Pardo, durante o período da Dominação Espanhola, também encontramos alguns registros de espanhóis ou hispano-americanos. Nesta paróquia, criada oficialmente em dezembro de 1762, a ocupação portuguesa havia se iniciado cerca de dez anos antes (1752), com a instalação da comitiva de Gomes Freire, demarcador português do Tratado de Madri. Inicialmente, a fortaleza de Jesus-Maria-José, ${ }^{36}$ estava subordinada à freguesia de Viamão, mas a partir de 1756 já existe um livro próprio de batismos. No entanto, encontra-se faltante o $2^{\circ}$ livro de batismos, que abrange justamente o período de 1763-1774. Conseguimos compensar parcialmente esta lacuna na documentação consultando o $1^{\circ}$ livro de Casamentos de Rio Pardo (1762-1786) e o 3ำ livro de batismos (1774-1783).

Nos registros de casamentos, conseguimos identificar cinco indivíduos de origem espanhola no período 1763-76: Miguel Mareco, paraguaio; Alexandre Rosales, "homem pardo", correntino; Valentim Dias e José Mariano Medina, buenairenses e Casemiro de Castilhos, possivelmente índio, natural de "São Nicolau de Buenos Aires". Todos eles se casaram com índias missioneiras, que vão se incorporando à sociedade portuguesa a partir da década de 1760. No livro de batismos, durante os anos de 1775 e 1776 , encontramos quatro registros de espanhóis ou hispano-americanos. Reaparece o "espanhol" Bernardo Vaquedano (Baquedano), como avô materno, um dos primeiros moradores dos campos de Viamão. Aparecem também Mariano de Castro, procedente de Lima (Peru) e Diogo Trilho, natural de Antiqueira (Espanha). O registro mais curioso refere-se a Romão castelhano, cujo escravo Francisco foi padrinho de batizado de "Jacinto, filho natural de Rosa, parda escrava de Jerônimo Machado". Esta foi a única vez que encontramos referência a um espanhol possuidor de escravos (com exceção de João Gonçalves Salgado, em Triunfo), o que pode ser um indicador da baixa condição social da maioria da população his-

XVIII. São Paulo, Companhia Editora Nacional, 1983, p. 32. A população de origem africana superava ligeiramente o contingente de origem européia. Isto fazia com que Triunfo fosse uma das freguesias com maior densidade populacional de escravos no Continente. Devido à pequena absorção de mão-de-obra escrava pela pecuária extensiva, podemos supor que a maioria dos cativos fossem utilizados em atividades domésticas ou agrícolas.

36 Existiam dois fortes com este nome no Rio Grande do Sul colonial: um situado em Rio Grande e outro em Rio Pardo. 
pânica ou hispano-americana residente no Continente do Rio Grande. ${ }^{37}$

Para concluir, temos um interessante relato sobre o contexto político-econômico desta região fronteiriça - a fronteira do Rio Pardo - durante o período da Dominação Espanhola, feito por Francisco José da Rocha, enviado ao Rio Grande no ano de 1771 pelo vicerei, o Marquês de Lavradio. Oficialmente, ele fora nomeado como sargento-mor do Regimento de Dragões de Rio Pardo; porém, a sua verdadeira ocupação era ser um observador in loco da conturbada situação rio-grandense, relatando tudo que via e ouvia ao vice-rei. O seu diagnóstico da região fronteiriça, nos meses iniciais de 1772, não era dos mais auspiciosos, pois assinalava que "os dois principais objetivos deste governo são as corridas do gado da Espanha (isto é, roubos), e a administração dos índios". Rocha fez duras críticas ao governador Antônio da Veiga e Andrade e a seus asseclas, como Rafael Pinto Bandeira, acusando-os de se apropriarem indevidamente do gado afanado aos domínios espanhóis. Aliás, a fraude seria prática generalizada, no seu entender, pois uma "infinidade de traficantes que negociam aqui com cavalos, éguas, mulas e bovinos, não são estancieiros locais, mas na sua maioria Paulistas das Minas", os quais evadiam as taxas dos animais exportados pela capitania enviando-os por caminhos onde inexistiam os registros. O Rio Grande, afirmou o informante do vice-rei, era "um ninho de ladrões". ${ }^{38}$ No entanto, ao que parece, os "ladrões" não eram exatamente os espanhóis ou os hispanoamericanos...

Não obstante as limitações inerentes ao tipo de documentação que privilegiamos (os registros paroquiais), acreditamos ter sido possível vislumbrar a inserção social e econômica dos espanhóis e hispano-americanos que povoaram o Continente do Rio Grande. Tanto na fronteira do Rio Grande, quanto nos campos de Viamão, a principal atividade dos hispânicos esteve associada à pecuária, seja como fornecedores de mão-de-obra especializada, seja como tropeiros ou carreteiros. A presença numericamente mais significativa dos hispano-americanos oriundos das cidades que compunham o circuito Buenos Aires-Potosi, torna-se perfei-

${ }^{37}$ IHGRGS/AMD n ${ }^{9} 49-1^{2}$ Livro de Casamentos de Rio Pardo (1762-1786), fls. 14v, 16, 87,195 e 235 \& AMD n $41-3^{\circ}$ Livro de Batismos de Rio Pardo (1774-1783), fls. 5v, $13 \mathrm{v}, 33 \mathrm{v}$ e 35 .

${ }^{38}$ Alden, op. cit., p. 120-123. O sargento-mor Rocha também denunciou os abusos do comissário dos índios, Pinto Carneiro, que se utilizaria indevidamente da mão-deobra dos indígenas aldeados, seja na sua própria propriedade e na de seus amigos, seja na realização de corridas ilegais, embolsando os lucros daí advindos. 
tamente inteligível se consideramos a relevância destes indivíduos dentro do mercado interno colonial sul-americano, possibilitando a integração econômica do espaço platino, através de reorientação de suas rotas comerciais para a região de ocupação lusitana. Como afirmamos acima, motivações estruturais (crise da mineração potosina e ascensão da mineração nas Minas Gerais) e conjunturais (rebeliões indígenas) possibilitaram a ocorrência desta nova orientação, a partir das décadas iniciais do século XVIII. Abertos os caminhos que ligavam o Rio Grande aos mercados internos consumidores da América portuguesa, tornou-se economicamente viável o comércio entre hispano-americanos e luso-brasileiros. Assim, ao invés da exclusão mútua, o contexto era de convivência e articulação entre zonas produtoras e mercados consumidores, integrando as esferas hispânica e lusitana da América meridional.

\section{Abreviaturas}

AHRS: $\quad$ Arquivo Histórico do Rio Grande do Sul.

IHGRGS/AMD: Instituto Histórico e Geográfico do Rio Grande do Sul/Arquivo Moacyr Domingues.

\section{Referências bibliográficas}

ALDEN, Dauril. Royal Government in colonial Brazil, with special reference to the administration of the Marquis of Lavradio, Viceroy (1769-1779). Berkeley \& Los Angeles: University of California Press, 1968.

CABRAL, Oswaldo R. Notas históricas sobre a fundação da póvoa de Santo Antônio dos Anjos da Laguna. In: Santo Antônio dos Anjos da Laguna: seus valores históricos e humanos. Florianópolis: Imprensa Oficial do Estado de SC, 1976.

CÉSAR, Guilhermino. História do Rio Grande do Sul - Periodo Colonial. Porto Alegre: Globo, 1970.

FARIA, Sheila de Castro. A colônia em movimento: fortuna e família no cotidiano colonial. Rio de Janeiro: Nova Fronteira, 1998.

FERNANDES, Domingos José Marques. Descrição corográfica, política, civil e militar da Capitania do Rio Grande do São Pedro do Sul (1804). In: Pesquisas - História, n. 15, Porto Alegre: Instituto Anchietano de Pesquisas, 1961.

FERRAZ, J. M. Os primeiros gaúchos da América Portuguesa. Porto Alegre: IEL/UCS, 1980.

FLORES, Moacyr. O tropeirismo e a economia colonial. In: SANTOS, Lucila M. S. (org.). Bom Jesus e o tropeirismo no Brasil Meridional. Porto Alegre: EST, 1995.

FRAGOSO, João Luís. Homens de Grossa Aventura. 2. ed. Rio de Janeiro: Civilização Brasileira, 1998.

FREITAS, Fernando de Castro. Triunfo - história, gente e legendas. Porto Alegre: Martins Livreiro, 1985.

GARAVAGLIA, Juan Carlos. Mercado interno y economía colonial. México, DF: Grijalbo, 1983.

HOLANDA, Sérgio Buarque de. Caminhos e fronteiras. 3. ed. São Paulo: Companhia das Letras, 1994. 
112 Estudos Ibero-Americanos. PUCRS, v. XXV, n. 2, p. 91-112, dezembro 1999

JACOBUS, André Luís. Registro de Viamão: novos aportes históricos e arqueológicos. In: SANTOS, Lucila M. S. (org.). Bom Jesus e o tropeirismo no Brasil Meridional. Porto Alegre: EST, 1995.

MATTOSO, José. Identificação de um país - ensaio sobre as origens de Portugal. Lisboa: Estampa, 1985.

MONTEIRO, John. Negros da terra. São Paulo: Companhia das Letras, 1994.

NEIS, Ruben. Guarda Velha de Viamão. Porto Alegre: EST/Sulina, 1975.

QUEIROZ, Maria Luiza B. A Vila do Rio Grande de São Pedro (1737-1822). Rio Grande: Ed. da FURG, 1987.

SANTOS, Corcino Medeiros dos. Economia e sociedade do Rio Grande do Sul - século XVIII. São Paulo: Nacional, 1983.

WEHLING, Arno. Formação do Brasil Colonial. Rio de Janeiro: 1994.

WESTPHALEN, Cecilia Maria. Verbetes "Tropas" e "Caminho do Viamão". In: SILVA, Maria Beatriz Nizza da (coord.). Dicionário da história da colonização portuguesa no Brasil. Lisboa: Verbo, 1994. 